\title{
Analysis of energy density of food in relation to energy intake regulation in human subjects
}

\author{
M. S. Westerterp-Plantenga* \\ Department of Human Biology, Maastricht University, P.O. Box 616, 6200 MD, Maastricht, The Netherlands
}

(Received 8 September 1999 - Revised 13 June 2000 - Accepted 3 October 2000)

\begin{abstract}
The relationship between energy density (ED) of food and drink consumption ad libitum and energy intake (EI) was analysed. EI was taken as average daily EI over the long term, and as EI during a single meal. Moreover, the distribution of EI over three ED categories was analysed. Average daily EI was related to ED of the food and drinks when ED was strongly influenced by specific macronutrients. When ED was strongly influenced by the weight of water, it was not related to EI. During a meal subjects monitored mainly weight, and to a lesser extent, the energy content of the food ingested. Therefore, covertly manipulated ED of a meal affected EI directly. The impact of ED on EI was modulated by dietary behaviours such as restraint. Overt manipulation of ED for 6 months showed that EI was adjusted to a decreased but not to an increased ED in dietary-unrestrained subjects, and that EI was adjusted to an increased but not to a decreased ED in dietary-restrained subjects. Knowledge of ED was shown to lead to an inverse relationship between portion sizes and ED during a meal. Average daily EI consisted of a distribution of EI over the three different categories of ED, so that obese women ate more of foods with a high ED and less of foods with a low ED compared with normal weight women (and nutritional guidelines). In conclusion, ED affected daily EI by means of macronutrient specific effects. EI from a meal with an unknown ED can become inversely related to EI through learning or conditioning. Therefore, the effect of ED on EI during a single meal observation cannot be extrapolated directly to the $24 \mathrm{~h}$ effect on EI. With regard to the treatment of obesity, a conscious decreased consumption of foods high in ED and an increase in consumption of lowED food is necessary to decrease and subsequently maintain body weight, particularly in subjects with a sedentary lifestyle.
\end{abstract}

Macronutrient composition: Dietary restraint: Obesity: Energy density: Energy intake regulation

\section{Energy intake and energy balance}

Normally, human subjects are on average in energy balance over a week (Edholm \& Fletcher, 1955). Man is a continuous nutrient metaboliser, but ingests food discontinuously. Therefore, tuning of energy intake (EI) to energy expenditure in order to maintain energy balance is required. This is achieved by an interaction of a variety of sensoric, gastrointestinal and metabolic factors that control the actual food intake pattern, i.e. meal size and meal frequency (Melanson et al. 1999a,b; Stubbs et al. 1999). In the short term, EI oscillates in the maintenance of energy balance.

\section{Metabolisable energy and macronutrient composition}

EI is not related in a straightforward fashion to the weight of food intake. Man derives his energy from the macronutrients carbohydrates, lipids, proteins and alcohol. The energy is released during the breakage of chemical bonds, and can be used for energy metabolism or can be converted or stored. Metabolisable energy is the gross energy minus energy in faeces and urine. Knowing the macronutrient composition of foods from chemical analysis, the metabolisable energy can be calculated by multiplying the weight of each nutrient by its metabolisable energy value, the Atwater factors. These are, for carbohydrate, protein, fat and alcohol, 16, 16, 37 and $29 \mathrm{~kJ} / \mathrm{g}$ respectively. The relevant food characteristics that play a role in regulation of EI are: energy content, macronutrient composition, weight, and energy density (ED) (Melanson et al. 1999a; Stubbs et al. 1999). Moreover, sensory characteristics of food (taste, texture,

\footnotetext{
Abbreviations: ED, energy density; EI, energy intake; WW, weight of water.

* Corresponding author: Dr M. S. Westerterp-Plantenga, fax +31 43367 0976, email m.westerterp@hb.unimaas.nl
} 
palatability) and variation in these characteristics also influence food intake (Drewnowski et al. 1992).

\section{Energy density}

Lately, attention has been paid to the role of ED in the regulation of EI (Westerterp-Plantenga et al. 1990a, 1996a,b; Stubbs et al. 1995, 1998a,b; Poppit \& Prentice, 1996; Rolls \& Bell, 1999; Westerterp-Plantenga, 2000a). ED is the total metabolisable energy from the different macronutrients, divided by the total weight of food and water consumption. This weight consists of the dry weight of these macronutrients (including the undigestible parts, e.g. non-digestible protein, resistant starch, fibre) plus the total weight of water (WW) consumed in and with the food.

\section{Relevant questions}

With regard to the role of ED in EI regulation, the relevant questions are:

(1) is daily energy intake related to the ED of food and drinks, and if so, which factors that determine ED contribute to this effect?

(2) is ED, energy content, or weight of food monitored subconsciously during food consumption?

(3) is food choice and portion size adjusted in response to ED?

\section{Plan of the remaining part of this paper}

(1) To gain insight into the effect of ED of food and drinks on average daily EI, three data sets from our laboratory were analysed (Goris \& Westerterp, 2000; Westerterp-Plantenga, 2000b). The possible relationship between EI and ED was assessed. Then, the factors that determine ED and the factors that determine EI were analysed. The significance of the determinants of ED for the relationship between EI and ED was determined;

(2) the role of ED in determining the amount of food intake during a single meal was discussed;

(3) the relationship between ED, portion size and food choice was analysed.

\section{The significance of the determinants of energy density for the relationship between energy intake and energy density}

In the three data sets which were analysed (1), food availability was ad libitum with regard to choice, amount and frequency. The first data set was obtained from a study in which sixteen dietitians (age 34 (SD 9, BMI 22.1 (SD $2 \cdot 3 \mathrm{~kg} / \mathrm{m}^{2}$ ) monitored their food intake for 1 week, using weighed food records. Their recording of EI was accurate, according to a method for the determination of water turnover using ${ }^{2} \mathrm{H}$ elimination, together with determination of body weight (Goris \& Westerterp, 2000). The protocol was executed twice, with feedback after the first time (during which they lost weight by under-eating). For the present analysis the food records produced the second time are used, during which no under-eating or under-recording occurred (Goris \& Westerterp, 2000). The second data set was from a study with female students (age 23 (SD 4), BMI $\left.22 \cdot 2(\mathrm{SD} 3 \cdot 2) \mathrm{kg} / \mathrm{m}^{2}\right)$ in a respiration chamber. The days on which they ate ad libitum, which were always preceded by a day during which they were fed in energy balance so that they did not have to compensate for the previous day, are used for the present analysis (Westerterp-Plantenga, $2000 \mathrm{~b}$ ). The third data set is similar to the second, but for male students (age 25 (SD 6), BMI 22.9 (SD 3.1) kg/m²) (Westerterp-Plantenga, 2000b).

Simple regression analysis was used. First, EI was analysed as a function of ED. Separately, EI was analysed as a function of the metabolisable energy provided by the macronutrients, and the gross weight of the macronutrients and WW. Third, ED was analysed as a function of the metabolisable energy provided by the macronutrients, and the gross weight of the macronutrients and WW.

\section{Calculation of energy intake and energy density}

As indicated earlier, ED is the total metabolisable energy consumed with the different macronutrients, divided by the dry weight of these macronutrients, which includes the undigestible parts, i.e. non-digestible protein $(\mathrm{N})$, resistant starch, and fibre, plus the total WW consumed. This can be written as:

$$
\mathrm{ED}=\frac{\text { carbohydrate }(\mathrm{kJ})+\operatorname{protein}(\mathrm{kJ})+\mathrm{fat}(\mathrm{kJ})+\text { alcohol }(\mathrm{kJ})}{(\text { carbohydrate }(\mathrm{g})+\text { protein }(\mathrm{g})+\text { fat }(\mathrm{g})+\text { alcohol }(\mathrm{g})+\text { water }(\mathrm{g})} .
$$

The computer program that was used for food intake analysis calculates metabolisable energy and gross weight, including fibre, non-digestible protein, resistant starch, etc. (Voorlichtings bureau voor de Voeding, 1992).

\section{The determinants of energy density and the relationship between energy intake and energy density}

The relative quantitative contributions of the determinants of ED and of EI in the three data sets were analysed, using a simple regression analysis. Table 1 shows EI $(\mathrm{kJ})$, energy $(\mathrm{kJ})$ from carbohydrate, protein and fat, as well as the weight $(\mathrm{g})$ of carbohydrate, protein, fat and water. It also shows ED, \% solids from total weight of food and macronutrient composition (\% energy) of the three data sets that were analysed. Table 2 gives the simple regression analysis for each of these three data sets, which shows the extent of linear correlation between the variables energy $(\mathrm{kJ})$ from carbohydrate, fat and protein, and the weight $(\mathrm{g})$ of carbohydrate, fat, protein and water $v$. ED, EI and \% solids respectively of the total weight of consumption.

The relationship EI:ED was as follows: data set 1 (dietitians) $r 0.38, P=0.0001$; data set 2 (women) $r 0.93$, $P=0.0001$; data set 3 (men) $r 0.17 ; P=0.27$. From the regression analyses it appears that EI was related to ED (data set 2), when the relationship of ED to the energy content and weight of the macronutrients was similar to the relationship of EI to these macronutrients. In data set 2 both ED and EI were related to the energy content and weight of 
Table 1. Energy intake and macronutrient composition from three data sets*

\begin{tabular}{|c|c|c|c|c|c|c|}
\hline & \multicolumn{2}{|c|}{ Data set 1} & \multicolumn{2}{|c|}{ Data set 2} & \multicolumn{2}{|c|}{ Data set 3} \\
\hline & \multicolumn{2}{|c|}{ Dietitians ( $n$ 16) } & \multicolumn{2}{|c|}{ Females in respiration chamber $(n 8)$} & \multicolumn{2}{|c|}{ Males in respiration chamber $(n 8)$} \\
\hline & Mean & SD & Mean & SD & Mean & SD \\
\hline El (MJ) & 9.4 & $2 \cdot 3$ & 9.7 & 1.0 & 14.5 & 3.4 \\
\hline$C(\mathrm{MJ})$ & 4.6 & $1 \cdot 2$ & $5 \cdot 4$ & 0.6 & $7 \cdot 0$ & $1 \cdot 8$ \\
\hline$P(M J)$ & $1 \cdot 3$ & 0.3 & 1.4 & 0.1 & $2 \cdot 2$ & 0.5 \\
\hline$F(M J)$ & $2 \cdot 9$ & 0.9 & 2.9 & 0.4 & $5 \cdot 3$ & 1.2 \\
\hline$C(g)$ & 288 & 77 & 338 & 36 & 438 & 115 \\
\hline$P(g)$ & 81 & 17 & 88 & 7 & 138 & 31 \\
\hline$F(g)$ & 78 & 25 & 78 & 11 & 143 & 32 \\
\hline W (g) & 2665 & 934 & 2903 & 97 & 2735 & 1478 \\
\hline ED $(\mathrm{kJ} / \mathrm{g})$ & 3.2 & 0.8 & $2 \cdot 8$ & 0.3 & 4.7 & $1 \cdot 7$ \\
\hline$\%$ Solid & 14 & 4 & 15 & 2 & 25 & 9 \\
\hline C:P:F: (\% energy) & \multicolumn{2}{|c|}{$49: 14: 31 \dagger$} & \multicolumn{2}{|c|}{$56: 14: 30$} & \multicolumn{2}{|c|}{$48: 15: 37$} \\
\hline
\end{tabular}

El, energy intake; C, carbohydrate; $P$, protein; F, fat; W, water, ED, energy density.

* Data set 1, Goris \& Westerterp (2000); data sets 2 and 3, Westerterp-Plantenga, (2000 b).

† $6 \%$ energy from alcohol.

the macronutrients but they were not related to WW. Furthermore, there was also a relationship between EI and ED (data set 1), when ED and EI were both related to the energy content and weight of the macronutrients, but ED was negatively related to WW whereas EI was positively related to WW. There was no relationship between EI and ED when their relationships with the different components were quite different (data set 3). Here, EI was mainly related to the energy content and weight of macronutrients, and also, positively to WW. ED was only negatively related to WW.

Similarly to ED, \% solids from total weight of food was related to EI (data set 1 and 2), when \% solids of total

Table 2. The extent of linear correlation between energy intake, energy density, \% solid of the total weight, and energy content and weight of the macronutrients, in three different data sets

\begin{tabular}{|c|c|c|c|c|}
\hline \multirow{2}{*}{ Data set† } & & \multicolumn{3}{|c|}{$r$} \\
\hline & & $\mathrm{El}$ & ED & $\%$ Solids \\
\hline \multirow[t]{7}{*}{1 (Dietitians, $n$ 16) } & $\mathrm{C}(\mathrm{kJ})$ & $0.81^{\star \star \star}$ & $0.28^{\star \star}$ & $0.33^{\star \star \star}$ \\
\hline & $\mathrm{P}(\mathrm{kJ})$ & $0.62^{\star \star \star}$ & 0.16 & 0.15 \\
\hline & $F(k J)$ & $0 \cdot 81^{\star \star \star}$ & $0.47^{\star \star \star}$ & $0.35^{\star \star \star}$ \\
\hline & $C(g)$ & $0 \cdot 81^{\star \star \star *}$ & $-0.28^{\star \star}$ & $0.33^{\star \star \star}$ \\
\hline & $P(g)$ & $0.62^{\star \star \star}$ & -0.16 & 0.15 \\
\hline & $F(g)$ & $0.81^{\star * *}$ & $-0.47^{\star \star \star}$ & $0.35^{\star * *}$ \\
\hline & W (g) & $0.33^{\star * *}$ & $-0.64^{\star \star \star}$ & $-0.65^{\star \star \star}$ \\
\hline \multirow[t]{7}{*}{2 (Females, $n 8$ ) } & $C(\mathrm{~kJ})$ & $0.54^{\star}$ & 0.50 & 0.35 \\
\hline & $\mathrm{P}(\mathrm{kJ})$ & 0.46 & 0.41 & 0.27 \\
\hline & $F(k J)$ & $0.77^{\star \star \star}$ & $0.85^{\star \star \star}$ & $0.72^{\star \star}$ \\
\hline & $C(g)$ & $0.54^{\star}$ & -0.50 & 0.35 \\
\hline & $P(g)$ & 0.46 & -0.41 & 0.27 \\
\hline & $F(g)$ & $0.77^{\star \star \star}$ & $-0.85^{\star \star \star}$ & $0.72^{\star \star}$ \\
\hline & W (g) & 0.21 & -0.15 & -0.04 \\
\hline \multirow[t]{7}{*}{3 (Males, $n 8$ ) } & $C(\mathrm{~kJ})$ & $0 \cdot 89^{\star \star \star}$ & 0.23 & 0.22 \\
\hline & $\mathrm{P}(\mathrm{kJ})$ & $0.98^{\star \star \star *}$ & 0.22 & 0.19 \\
\hline & $\mathrm{F}(\mathrm{kJ})$ & $0.97^{\star \star *}$ & 0.27 & 0.26 \\
\hline & $C(g)$ & $0 \cdot 89^{\star \star \star}$ & -0.23 & 0.22 \\
\hline & $P(g)$ & $0.98^{\star \star *}$ & -0.22 & 0.19 \\
\hline & $F(g)$ & $0.97^{\star \star *}$ & -0.27 & 0.26 \\
\hline & W (g) & $0.66^{\star \star \star}$ & $-0.77^{\star \star \star}$ & $-0.76^{\star \star \star}$ \\
\hline
\end{tabular}

$\mathrm{El}$, energy intake; ED, energy density; C, carbohydrate; P, protein; $F$, fat; W, water.

${ }^{\star} P<0.05,{ }^{* *} P<0.01,{ }^{* \star *} P<0.001$.

† Data set 1, Goris \& Westerterp (2000); data sets 2 and 3, WesterterpPlantenga (2000b). weight of food was related to the macronutrients, but not when it was only related to WW.

From the simple regression analyses it appears that ED can be predicted significantly by the weight $(\mathrm{g})$ of fat, carbohydrate and water and by the energy $(\mathrm{kJ})$ from fat and carbohydrate (Table 2). The variation in the relative proportion of protein was small, so it does not contribute much to the variation in ED.

ED represents energy (kJ)/weight, since the Atwater factors are defined in this way. ED does not represent energy $(\mathrm{kJ}) /$ volume. If volume is used, then one has to take the specific weight of the food into account, since weight $=$ volume $\times$ specific gravity. Specific gravity of a food recipe changes, for instance, when air is added, as, for example, in a soufflé. This might have a very short-term effect, but it is by definition not an ED effect. Sometimes both weight and volume are used (Rolls \& Bell, 1999), which might slightly confuse the interpretation of ED.

\section{Explanations of the possible relationships between energy intake and energy density}

The analysis on the three different data sets shows three different outcomes. The difference between the outcomes of data sets 1 and 2 is determined by the difference in variation in WW of total consumption. In data set 1 there was a variation in the WW consumed, which affected ED negatively and which was positively related to EI. In data set 2 the variation in the WW was too small to contribute to ED and EI. Both data sets show contributions of variations in macronutrients to ED and to EI; in both data sets EI was positively related to ED.

The difference between data set 1 and 3 is determined by the difference in the variation in macronutrient intake. Data set 1 shows a variation in macronutrients (carbohydrate and fat), which affected ED and which was positively related to EI. In data set 3 there was too little variation in macronutrient intake to contribute to ED. Both data sets 1 and 3 show the positive relationship between WW and EI, and the negative relationship between WW and ED. Data set 1 implies a relationship between EI and ED; data set 3 lacks this type of relationship. Data sets 2 and 3 show the 
largest differences. In data set 2 the relationship between EI and ED is determined by the weight and energy content of fat, and WW does not have any significance for this relationship. In data set 3 a relationship between EI and ED is absent, because of the dominant effect of WW on ED, the lack of effect of the macronutrients on ED, and the dominant effect of the macronutrients on EI.

From the differences between these three outcomes it was concluded that ED was related to EI, when ED was related to the energy content and the weight of macronutrients (data sets 1 and 2), and possibly but not necessarily to WW (data set 1). When water was the dominant component (WW) of ED, EI was not related to ED (data set 3). In other words, when the variation in ED was only determined by WW, ED did not play a role in EI regulation. This means that EI became independent of ED, when only the range in the WW determined the range of ED.

When EI was also determined by WW, WW correlated positively with EI, whereas it correlated negatively with ED. This concerns WW in the food, which is inclusive in food intake. It means that the EI from the food cannot take place without the accompanying water.

The analysis of the effect of \% solids of total weight of food shows similar results to that of ED. It is important to discriminate between \% solids and liquid, in a way that \% solids only includes the dry weight of the foods and \% liquid only includes the water in- and outside the foods. Otherwise the discrimination becomes arbitrary, e.g. a soup with a high total dry weight would be categorised as liquid, whereas a cucumber with a high WW would be categorised as solid.

The relationship between ED and EI is strong when the separate relationships of ED and EI to the macronutrients are similar. All macronutrients explained the variation in EI, with the weight of fat contributing most to EI, and also to ED. As soon as the effect of WW on ED became relatively large, the positive relationship between ED and EI became weaker, and disappeared.

Therefore, we cannot simply substitute the effects of the different macronutrients on EI regulation by the effect of ED (macronutrients and possibly WW, or mainly WW), as it is sometimes suggested (Rolls \& Bell, 1999). Such a suggestion is based upon studies in which macronutrient compositions remained the same, but the dilution in the foods varied. From the dilution range of the same type of food the EI was higher from the less diluted food and lower from the more diluted food (Rolls \& Bell, 1999). Since the relative contributions of the macronutrients were kept constant, the only effect on ED must have been WW. When we showed a large effect of WW on ED, such as in our data set 3, the relationship between EI and ED was absent, and it was the energy content and weight of the macronutrients that determined EI, irrespective of WW. In our data sets only WW was related to EI positively, which must have been the water in the food, as is discussed earlier. If the relationship between EI and ED is absent, it means that EI can consist of foods of any ED. From the observation that EI is greater when the food is less diluted and lower when the food is more diluted (Rolls \& Bell, 1999), we cannot conclude whether this implies a significant relationship between EI and ED since the regression analysis is not known.

\section{Specific effects of the determinants of energy density on energy intake}

Water. With regard to WW, there is evidence on the possible role of water intake in satiety from a study by Himaya \& Louis Sylvestre (1998). When the water is part of the food, it affects stomach emptying, and thus it affects satiety. When water is outside the food, it empties from the stomach straightaway, and does not affect stomach emptying of the other food, therefore it does not affect satiety. The rate of gastric emptying is largely controlled by the energy content of the stomach (Brouns et al. 1987) and the stretch receptors in the stomach signal energy content to the brain (Rayner, 1992). Thus, when water is part of the food it may contribute positively to satiety.

Fat. With regard to the weight of fat, many studies include examples of a change in \% energy from fat, changing ED and subsequently affecting EI, e.g. Lissner et al. (1987), Kendall et al. (1991), Blundell et al. (1993), Green et al. (1994), Hulshof et al. (1995), Rolls (1995), Stubbs et al. (1995, 1996, 1998a,b), Cotton et al. (1996), Poppit \& Prentice (1996), Westerterp-Plantenga et al. (1997a,b, 1998, 1999), Hill et al. (1998), Kelly et al. (1998).

The possible implication that fat replacement including reduction of energy content may have for the treatment of obesity, or for contribution to weight maintenance, appears not to be straightforward. A number of studies show different responses due to different subject characteristics, e.g. dietary restraint. In a 6 month reduced-fat $v$. full-fat study in dietary-restrained and -unrestrained men and women, we found that a reduced-fat diet in combination with unrestrained eating behaviour (which resulted in EI compensation), contributed to weight maintenance. Weight reduction was the consequence of a reduced-fat diet in combination with restrained, non-compensatory eating behaviour. A full-fat diet combined with unrestrained eating behaviour led to increased EI, although the gain in body weight did not reach statistical significance $(P=$ 0.07). Restrained eating behaviour with a full-fat diet prevented an increase in EI and body weight. Thus, the dietary-restrained subjects compensated with their EI for the increase in ED, whereas the dietary-unrestrained subjects compensated with their EI for the decrease in ED (Fig. 1; Westerterp-Plantenga et al. 1998).

In a study with covert fat replacement ( $23 \mathrm{~g}$ ) by sucrose polyester during breakfast and lunch on two sequential weekdays, in dietary-restrained and -unrestrained women, we showed an EI reduction of $0.7 \mathrm{MJ} / \mathrm{d}(P<0.05)$ in the normal weight dietary-restrained women, but not in the dietary-unrestrained. In the dietary-unrestrained, EI reduction was $0.5 \mathrm{MJ} / \mathrm{d}(\mathrm{NS})$. These EI reductions resulted in $22 \%$ EI compensation for the EI prevented by fat replacement in the dietary-restrained subjects, and in $44 \%$ EI compensation in the subjects who lacked dietary restraint. The two sequential weekdays were part of 1 week when complete food intake was assessed; the two sequential 

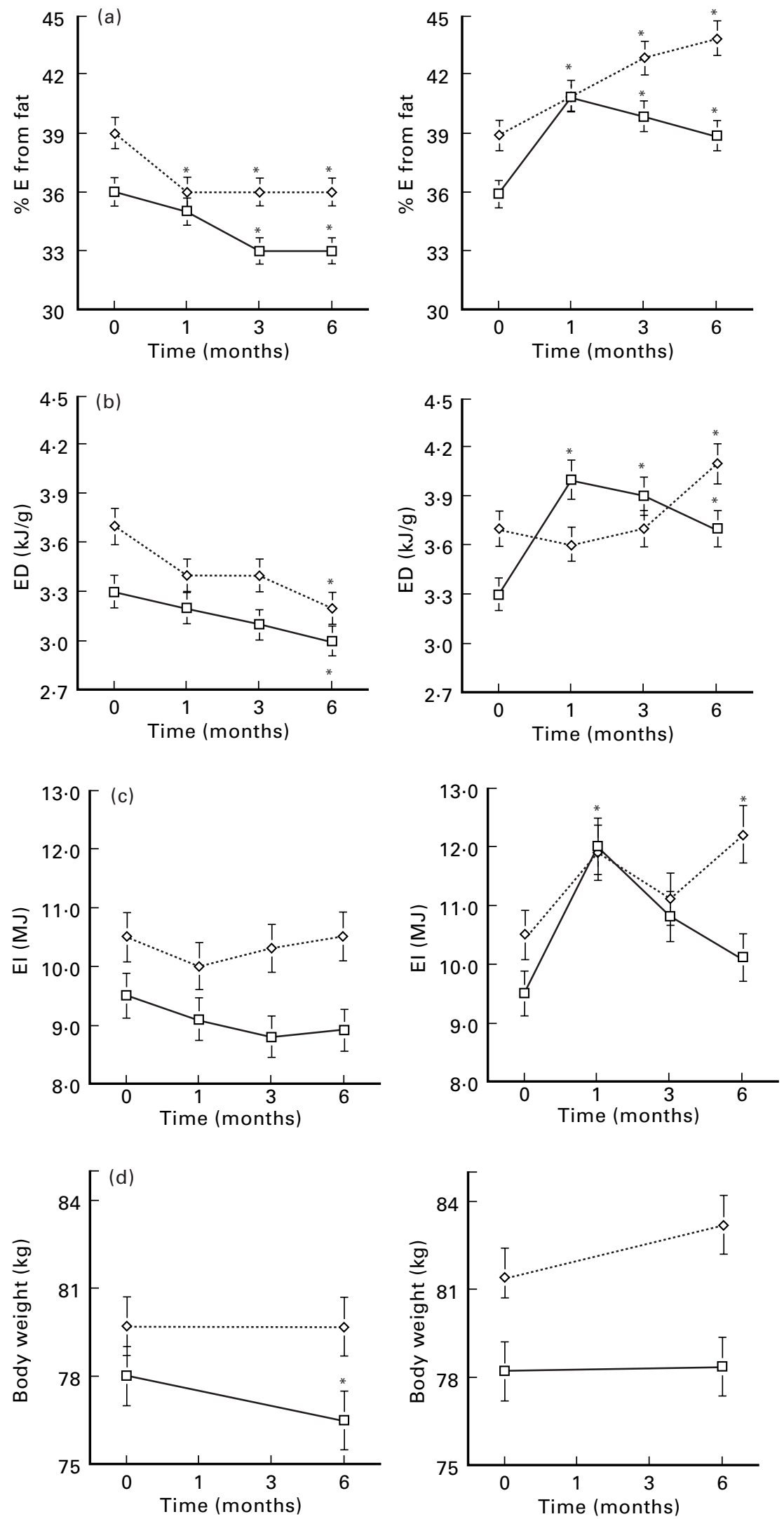

Fig. 1. (a) Percentage energy (\%E) from fat, (b) energy density (ED) of total consumption, (c) average daily energy intake (EI) and (d) body weight in a 6 month trial in which dietary-restrained and -unrestrained men and women were maintained on a reduced-fat (left hand panels) or full-fat (right hand panels) diet (Westerterp-Plantenga et al. 1998). $\square$, Dietary-restrained subjects; $\diamond$, dietary-unrestrained subjects. Values are means with standard deviations shown by vertical bars. Mean values were significantly different from those at baseline: ${ }^{\star} P<0.05$. 
placebo days were part of another week with assessment of complete food intake. During another 2 weeks, subjects received a fresh box with labelled snacks every day. In 1 of these 2 weeks, all snacks in the boxes were full-fat snacks, and in the other of the 2 weeks, all snacks were present in both a full-fat and in a reduced-fat including reduced-energy form. When fat replacement was overtly present in snacks, the dietary-unrestrained and the post-obese dietary-restrained women showed an EI reduction of $0.6-0.7 \mathrm{MJ} / \mathrm{d}(P<0.05)$, but the dietaryrestrained women showed a non-significant EI reduction of 0.4-0.5 MJ/d (Westerterp-Plantenga et al. 1997a). In comparison, Hulshof et al. (1995) found, in a $12 \mathrm{~d}$ study with sucrose polyester as a fat replacer, no differences in any aspect of appetite in women, probably because the EI from the meals using the fat replacer was at the subjects' normal level, whereas the EI from the meals using fat was above their normal level. These results suggested short-term beneficial effects of fat replacement including reduction of ED, on EI and fat intake.

Carbohydrate. With regard to the role of carbohydrate in relation to $\mathrm{ED}$, simple carbohydrates have received attention with regard to effects of their replacement by sweeteners, in order to lower ED, and subsequently EI. In this respect Drewnowski (1999) considers that the theoretical reduced EI with low ED foods, leading to body weight loss is arguable. There is also the question as to whether energy-dilute foods are as palatable as the more energydense foods. Generally high ED equals high palatability and vice versa (Drewnowski, 1999). Intense sweeteners may represent an exception to the rule, since they maintain sweetness while reducing ED (Drewnowski, 1999). Results from studies on this topic appear to be controversial. For instance, aspartame has been shown to increase (Blundell \& Hill, 1986; Rogers et al. 1988), decrease (Rogers et al. 1990; Rolls et al. 1990), or not to affect (Mattes, 1990; Black et al. 1991) hunger or food intake in human subjects. A high inter-subject variability was observed in a study on blood glucose and meal patterns in time-blinded males after an aspartame or carbohydrate preload and included all three of the responses mentioned earlier (Melanson et al. 1999c). Aspartame ingestion was followed by blood glucose transient declines (40\% of subjects), increases $(20 \%)$, or no change $(40 \%)$. These patterns were related to the subjects' perception of sweetness of the drink, and were predictive of subsequent intakes. A perception of very sweet coincided with a decline in blood glucose and relatively less suppression of hunger. A perception of much less sweet coincided with an increase in blood glucose and hunger suppression (Fig. 2; Melanson et al. 1999c). From these experiments it was concluded that the possible effect of lowering ED by replacing the use of simple carbohydrates depends on the sweetness perception of the substitute. If the substitute is not perceived as very sweet, it is perceived as energy, and an increase in blood glucose and hunger suppression follows. When the substitute is perceived as very sweet, it does not suppress hunger. In this respect Holt et al. (1991) concluded that satiety power and hedonic preferences were inversely linked. In our studies on artificial sweeteners this was also the case: sweetness perception varied among subjects and showed differences in the hunger suppression responses (Melanson et al. 1999c).

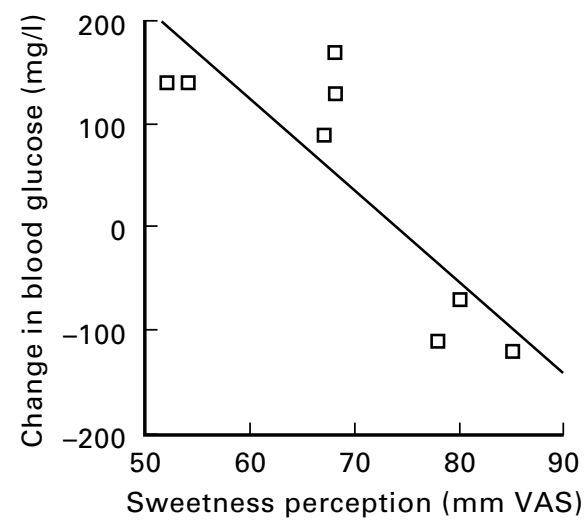

Fig. 2. Relationship between sweetness perception of aspartame and change in blood glucose level in young male subjects. A perception of less sweet coincided with an increase in blood glucose and hunger suppression (Melanson et al. 1999c). VAS, visual analogue scale.

Macronutrients. With regard to the physiological effects of all macronutrients on EI, Stubbs et al. (1999) suggest that different effects from the different macronutrients are caused by a hierarchy in satiety, with protein $>$ carbohydrate $>$ fat, and a priority in oxidation in the same sequence. Our studies showed that these effects occurred simultaneously, i.e. a relatively high satiety and thermogenesis on a diet rich in protein and carbohydrate $v$. a highfat diet, during a $24 \mathrm{~h}$ stay in the respiration chamber (Westerterp-Plantenga et al. 1999). This is an example of an increased energy expenditure at rest, implying an increased $\mathrm{O}_{2}$ consumption and an increase in body temperature, which has shown to be related to satiety (Westerterp-Plantenga et al. 1990b).

\section{Conclusion}

ED was related to EI when the macronutrients fat and carbohydrate determined ED to a large extent, while WW determined ED to a minor extent. Analysis of our data showed that ED does not have a significant relationship with EI when ED was only determined by WW. Long-term effects of ED on EI interact with subject specific behaviour, especially dietary restraint. Then EI was adjusted to a decreased but not to an increased ED in dietary-unrestrained subjects, and EI was adjusted to an increased but not to a decreased ED in dietary-restrained subjects.

\section{Food intake during a meal in relation to energy density and macronutrient composition}

Food intake during a meal (2) was studied using cumulative food intake curves (Westerterp-Plantenga et al. 1990a, 2000a; Westerterp-Plantenga \& Verwegen, 1999) obtained by monitoring eating from a plate placed on a scale built into a table, and connected to a digital computer. They describe and integrate variables of consumption of an $a d$ libitum single course meal, i.e. meal size, meal duration, eating rate, change in eating rate, bite size, and bite frequency (Westerterp-Plantenga et al. 1990a, 2000a; Westerterp-Plantenga \& Verwegen, 1999). In one set of 

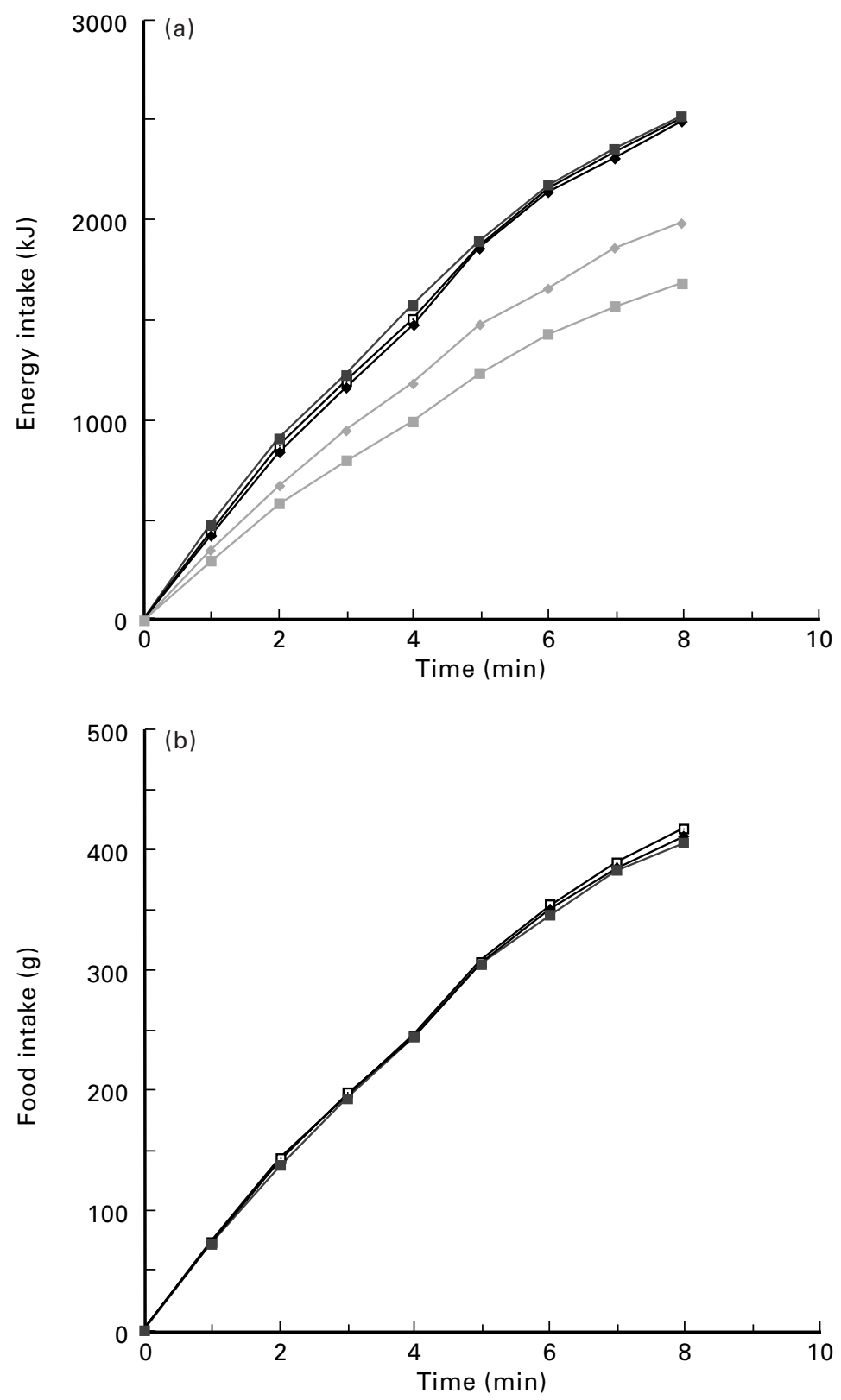

Fig. 3. Example of cumulative food intake in $\mathrm{kJ}$ (a) and in $\mathrm{g}$ (b) over time of five similar meals differing only in energy density and macronutrient composition. Subjects were normal weight women. Carbohydrate:protein:fat: high carbohydrate, 70:10:20; high protein, 50:30:20; high fat, 50:10:40 (WesterterpPlantenga, 1990a, 2000a). (a):,$-- 6.1 \mathrm{~kJ} / \mathrm{g}$, high carbohydrate; $-\rightarrow$, $6.1 \mathrm{~kJ} / \mathrm{g}$, high protein; $-\otimes-6.1 \mathrm{~kJ} / \mathrm{g}$, high fat; $\neg, 4.8 \mathrm{~kJ} / \mathrm{g} ;--, 4.0 \mathrm{~kJ} / \mathrm{g}$. (b):,$-- 4.0 \mathrm{~kJ} / \mathrm{g} ;-, 4.8 \mathrm{~kJ} / \mathrm{g} ;-\infty-6.1 \mathrm{~kJ} / \mathrm{g}$.

experiments the ED of an otherwise familiar meal was covertly changed from $4.8 \mathrm{~kJ} / \mathrm{g}$ to $6 \cdot 1 \mathrm{~kJ} / \mathrm{g}$ by replacing some of the food by tasteless protein or carbohydrate powders or by a 'beurre manié'. A beurre manié is a cold mixture of oil with a little flour that can be added to a warm sauce just before serving, without affecting the taste of the sauce. This resulted in a change in macronutrient compositions from 55:15:30\% energy (carbohydrate: protein:fat) to $50: 10: 40$ (high fat), 70:10:20 (high carbohydrate), 50:30:20 (high protein) \% energy (Westerterp-Plantenga et al. 1990a).

In another set of experiments ED was decreased to $4.0 \mathrm{~kJ} / \mathrm{g}$ by adding $20 \mathrm{~g}$ fibre (guar gum) to the meals with the basic macronutrient composition (55:15:30 (carbohydrate:protein:fat)).

A covert change in ED of an otherwise familiar meal from $4.8 \mathrm{~kJ} / \mathrm{g}$ to $6.1 \mathrm{~kJ} / \mathrm{g}$ caused no change in the cumulative intake curve variables (Westerterp-Plantenga 
et al. 1990a). In addition, the shape of the individual cumulative food intake and satiation curves showed very little variability despite experimentally energy-enriched meals (Fig. 3; Westerterp-Plantenga et al. 1990a, 2000a). Moreover, we found that with meals with the basic macronutrient composition, ED was decreased to $4.0 \mathrm{~kJ} / \mathrm{g}$ by adding $20 \mathrm{~g}$ fibre (guar gum), the amount eaten (g), meal duration, and eating rate did not change. However, after the energy-enriched lunch meals, as well as after the energy-diluted meals with fibre, subjects reported feeling more satiated in the afternoon, skipping their afternoon snacks and showing a longer intermeal interval from lunch to dinner (Westerterp-Plantenga et al. 1996b, 2000a).

\section{The effect of energy density on energy intake during a meal is mediated by conditioning}

From these observations we conclude that during a meal, subjects mainly monitored their food intake by weight of the food consumed over time. No changes in cumulative food intake variables were shown in relation to ED (4$6 \mathrm{~kJ} / \mathrm{g}$ ), macronutrient composition and fibre content of a meal within a certain range. However, it was also shown that a change in EI achieved this way showed compensatory effects on the subsequent meal interval and meal size in certain cases (Westerterp-Plantenga et al. 1996b, 2000a).

Similar results from subjects monitoring weight of food rather than energy content of food during a meal were reported by Bell et al. (1998). In a study by Yeomans (1996), however, it appeared that palatability interacted with monitoring weight of food intake: increased palatability by adding a small amount of oregano increased weight of food intake and decreased palatability by addition of excess oregano tended to decrease food intake. Given the previous observation that subjects did not monitor EI at least during a first encounter with a meal (WesterterpPlantenga et al. 1990a), it was hypothesised that conditioning might take place in order to determine portion size in relation to the energy content of the meal. Since most meals are familiar, conditioning of energy content might have taken place this way. Some evidence for this, at least in dietary-restrained subjects, has been obtained when the subjects were asked to estimate their forthcoming ingestion of a familiar meal. Accuracy appeared to be positively correlated to dietary restraint. While eating an unfamiliar meal this (unconscious) learning aspect of eating behaviour was not yet present, but it was achieved during the second confrontation with the unfamiliar meal (Westerterp-Plantenga et al. 1992a). Moreover, when diet-induced thermogenesis was assessed under these circumstances, it was significantly greater in the first encounter with the unfamiliar meal, compared with the diet-induced thermogenesis of the encounter with the familiar meal, and also when compared with the diet-induced thermogenesis of the second encounter with the unfamiliar meal. It appears that the facultative part of the diet-induced thermogenesis had increased due to a higher alertness during the first encounter with the unfamiliar meal (Westerterp-Plantenga et al. 1992b). In addition Spiegel (1973) concluded that at a first encounter, subjects failed to compensate for changes in the ED of a preload. However, when she performed more

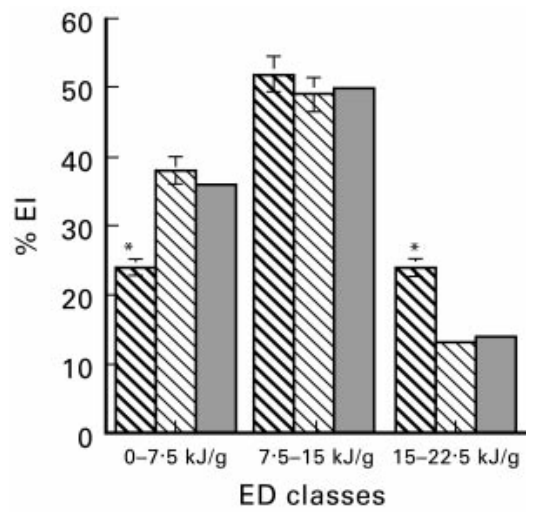

Fig. 4. Percentages of energy intake (EI) from different energy density (ED) categories of food in women. $\mathbb{\nabla}$, Obese women; $\mathbb{\nabla}$, normal weight women; 國, guidelines. Values are means with standard deviations shown by vertical bars. Mean values were significantly different from values for the normal weight women, and from the guidelines: ${ }^{*} P<0.015$ (Westerterp-Plantenga et al. 1996a).

experiments on consecutive days (2-5 d) compensation improved up to $87 \%$, albeit not in all subjects (Spiegel, 1973).

\section{Conclusion}

With regard to the effect of ED on EI during a meal, conditioning might play a role. This has been generalised in that portion sizes appear to be culturally related to the food types (Westerterp-Plantenga et al. 1996a). However, in the course of the day compensatory responses, e.g. to increased ED or to increased fibre contents have also been observed.

\section{Energy intake adjustment to energy density depends on energy requirements}

To assess the effect of ED of foods on food choice and portion size (3), we examined EI in relation to ED of foods in obese and non-obese women (Westerterp-Plantenga et al. 1996a).

From sixty-eight subjects (thirty-four obese and thirtyfour non-obese women, matched for age 20-50 years) controlled food intake diaries of two weekdays and one weekend day were analysed. The obese women showed a food intake distribution over three classes of ED of foods, i.e. $0-7.5 \mathrm{~kJ} / \mathrm{g}, 7.5-15 \mathrm{~kJ} / \mathrm{g}$ and $15-22.5 \mathrm{~kJ} / \mathrm{g}$ of 24,52 and $24 \%$ energy respectively, with a macronutrient composition 39:17:44 (carbohydrate:protein:fat) \% energy. In the non-obese women the food intake distribution over these three classes was 38, 49 and $13 \%$ energy, with a macronutrient composition of 46:17:37 (carbohydrate: protein:fat) $\%$ energy. The distribution in the obese women was significantly different from the values of the non-obese and from the Dutch food guidelines values (Fig. 4; Westerterp-Plantenga et al. 1996a). Energy intake per meal increased from the first to the third meal of a day: $\%$ energy from fat increased and \% energy from carbohydrate decreased. The intake of the non-obese women was: breakfast $1.2 \mathrm{MJ}, 18 \%$ energy from fat, $65 \%$ energy from carbohydrate; dinner $4.1 \mathrm{MJ}, 42 \%$ 


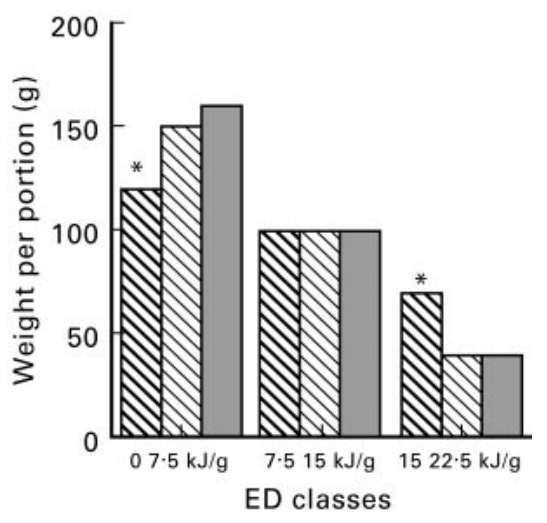

Fig. 5. Mean weight per portion from the different energy density (ED) categories in women. $\mathbb{\nabla}$, Obese women; $\mathbb{\nabla}$, normal weight women; 圆, guidelines. Mean values were significantly different from the values for normal weight women and from the guidelines: ${ }^{*} P<$ 0.015 (Westerterp-Plantenga et al. 1996a).

energy from fat, $40 \%$ energy from carbohydrate. The intake for the obese women was: breakfast $1.3 \mathrm{MJ}, 38 \%$ energy from fat, $45 \%$ energy from carbohydrate; dinner $4.5 \mathrm{MJ}, 46 \%$ energy from fat, and $37 \%$ energy from carbohydrate. With regard to portion sizes it appeared that the obese women took larger portions of food with a highED than the non-obese did, and also larger than standard sizes (Westerterp-Plantenga et al. 1996a; for standard portion sizes see Hulshof et al. 1992). Likewise, the obese women took smaller portions of food with a low ED in comparison with the non-obese and in comparison with the standard sizes. In the non-obese, portion sizes were almost standard portion sizes (Fig. 5; Westerterp-Plantenga et al. 1996a).

For individuals with different energy needs, e.g. normal weight $v$. overweight and obese, portion size, ED and meal frequency play a role in attempts to achieve energy balance. The result is a distribution of EI over three distinguishable ED categories. In order to consume a certain amount of energy during a day a certain weight of food needs to be consumed, which cannot be too large because of stomach filling. This was achieved by a relatively large consumption of food (50\% total daily EI) from the ED category of 7.5$15.0 \mathrm{~kJ} / \mathrm{g}$ in the obese as well as in the non-obese. These observations can easily be understood because most of the food items belonging to this ED category are staple foods like bread, potatoes, rice and spaghetti. Such products are rich in carbohydrate, and with a $50 \%$ energy consumption from this category, a large part of the daily carbohydrate intake will be reached. Any adjustment of EI to ED must then be achieved by varying intakes in the lower and higher ED categories.

The obese women consumed $24 \%$ energy from the lowest ED category (14\% energy less than the non-obese) and $24 \%$ energy from the highest ED category $(11 \%$ energy more than the non-obese). Physiologically this seems a perfect adjustment, and we cannot conclude that the obese women showed a lack of sensitivity to ED, e.g. to a physiological regulation mechanism. For the obese women it might be easier to choose products with a relatively lower weight and high ED, as they showed in the relatively large portions of high-ED foods and relatively small portions of low-ED foods. In addition, from experiments by Drewnowski et al. (1992) it is known that the obese people like high-fat foods (belonging to the third category) better than other foods, which results usually in a relatively higher fat:carbohydrate ratio and in those consuming high-ED food.

The non-obese women consumed $38 \%$ energy from the lowest and $13 \%$ energy from the highest ED category. They had portion sizes and a macronutrient composition that did not differ significantly from the composition based on the Dutch food guidelines (Voorlichtingsbureau voor de Voeding, 1992). With regard to the variation of portion sizes in relation to ED of the food, Green et al. (1994) reported that in healthy non-obese males, portion size was adapted to a certain extent to ED of snacks of 7.6-16.5 kJ/ $\mathrm{g}$. The non-obese as well as the obese women showed a clear pattern of energy and macronutrient intake during the day. EI as well as fat intake increased during the day and carbohydrate intake decreased, albeit that the \% energy from fat and \% energy from carbohydrate at the start and at the end of the day were different between the obese and non-obese subjects. De Castro (1987) showed the same pattern. The temporal switch from \% energy as carbohydrate to fat occurred earlier in the day in the obese subjects, and more gradually in the non-obese subjects. In addition, the obese ate more at their evening meal than the non-obese did (Westerterp-Plantenga et al. 1996a).

From these analyses some suggestions for weightreduction diets may be made. First, consumption of highED food could be replaced by consumption of low-ED food by switching from the highest to the lowest category, in order to achieve the ED distribution which is shown by the non-obese as well as by the guidelines. Second, considering the energy and macronutrient intake pattern over $1 \mathrm{~d}$, interventions would have relatively bigger effects in the afternoon and evening, when usually the relatively higherED foods appear to be consumed. Both dietary suggestions imply a conscious adjustment to eating more food of low ED and less food of high ED. This may be necessary in all obese subjects, and with regard to prevention of obesity, to vulnerable (i.e. overweight) subjects, in order to maintain body weight at a healthy level in subjects with a sedentary lifestyle.

\section{Concluding remarks}

In conclusion, ED was related to EI when the macronutrients fat and carbohydrate determined ED to a great extent, and while WW determined ED to a minor extent. ED did not have a significant relationship with EI when ED was only determined by WW. EI was positively related to WW in the food, i.e. when the water was part of the food. ED was negatively related to the water intake of total consumption. When water intake was the main determinant of the ED, there was no relationship between EI and ED.

Long-term effects of changes in ED on EI interact with subject-specific behaviour, especially dietary restraint. Then EI was adjusted to a decreased but not to an increased ED in dietary-unrestrained subjects, and to an 
increased but not to a decreased ED in dietary-restrained subjects.

Estimation of prospective EI for a single meal probably takes place unconsciously and appears as a conditioned effect. This has been generalised in that portion sizes appear to be culturally related to the food types. However, in the course of the day compensatory responses, e.g. to increased ED or to increased fibre contents have been observed.

Food choice adjustment to ED categories appeared to interact with energy requirements, e.g. the obese show a different distribution of food intake from different ED categories compared with normal weight subjects.

With regard to the treatment of obesity, a conscious shift in food choice of high-ED foods to low-ED foods is recommended.

\section{Acknowledgements}

Annelies Goris is gratefully acknowledged for providing me with her data. In addition, Caroline Cilissen, Sigrid Top, Pascale van Hoydonck, Heidi Strobbe and Stefanie van de Kerkhoven are acknowledged for their support in collecting part of the data.

\section{References}

Bell EA, Castellanos VH, Pelkman CL, Thorwart ML \& Rolls BJ (1998) Energy density of foods affects energy intake in normalweight women. American Journal of Clinical Nutrition 67, 412-420.

Black RM, Tanaka P, Leiter LA \& Anderson GH (1991) Soft drinks with aspartame: Effect on subjective hunger, food selection, and food intake of young adult males. Physiology \& Behavior 49, 803-810.

Blundell JE, Burley VJ, Cotton JR \& Lawton CL (1993) Dietary fat and the control of energy intake: evaluating the effects of fat on meal size and postmeal satiety. American Journal of Clinical Nutrition 57, 722S-728S.

Blundell JE \& Hill AJ (1986) Paradoxical effects of an intense sweetener (aspartame) on appetite. The Lancet i, 1092-1093.

Brouns F, Saris WHM \& Rehrer NJ (1987) Abdominal complaints and gastrointestinal function during long-lasting exercise. International Journal of Sports Medicine 8, 175-189.

Castro JM de (1987) Circadian rhythms of the spontaneous meal pattern, macronutrient intake and mood of humans. Physiology \& Behavior 40, 437-446.

Cotton JR, Burley VJ, Weststrate JA \& Blundell JE (1996) Fat substitution and food intake: effect of replacing fat with sucrose polyester at lunch or evening meals. British Journal of Nutrition 75, 545-556.

Drewnowski A (1999) Intense sweeteners and energy density of foods: implication for weight control. European Journal of Clinical Nutrition 53, 757-763.

Drewnowski A, Kurth C, Holden-Wiltse J \& Saari J (1992) Food preferences in human obesity: carbohydrates versus fats. Appetite 18, 207-221.

Edholm OG \& Fletcher JG (1955) The energy expenditure and food intake of individual men. British Journal of Nutrition 9, 286-300.

Goris AHC \& Westerterp KR (2000) Improved reporting of habitual food intake after confrontation with earlier results on food reporting. British Journal of Nutrition 83, 363-369.

Green SM, Burley VJ \& Blundell J (1994) Effect of fat- and sucrose-containing foods on the size of eating episodes and energy intake in lean males: potential for causing overconsumption. European Journal of Clinical Nutrition 48, $547-555$.

Hill JO, Seagle HM, Johnson SL, Smith S, Reed GW, Tran ZV, Cooper S, Stone M \& Peters JC (1998) Effects of 14d of covert substitution of olestra for conventional fat on spontaneous food intake. American Journal of Clinical Nutrition 67, 1178-1185.

Himaya A \& Louis-Sylvestre J (1998) The effect of soup on satiation. Appetite 30, 199-210.

Holt SHA, Brand Miller JC, Petocz P \& Farmakalidis E (1991) A satiety index of common foods. European Journal of Clinical Nutrition 49, 675-690.

Hulshof KFAM, van der Heijden LJM, Donders-Engelem M \& Lowik MRH (1992) TNO-rapport V 92.003. Maten, gewichten en code nummers 1992. TNO-voeding Zeist, Landbouw universiteit Wageninjen (TNO-report V 92.003. Measures, weights and code-numbers 1992. TNO-Nutrition Zeist, Agricultural University Wageningen). Wageningen: TNO-Nutrition Zeist and Agricultural University Wageningen.

Hulshof T, De Graaf C \& Weststrate JA (1995) Short-term satiating effect of the fat replacer sucrose polyester (SPE) in man. British Journal of Nutrition 74, 569-585.

Kendall A, Levitsky DA, Strupp BJ \& Lissner L (1991) Weightloss on a low fat diet: consequence of the impression of the control of food intake in humans. American Journal of Clinical Nutrition 53, 1124-1129.

Kelly SM, Shorthouse M, Cotterel JC, Riordan AM, Lee AJ, Thurnham DI, Hanka R \& Hunter JO (1998) A 3 month doubleblind controlled trial of feeding with sucrose polyester in human volunteers. British Journal of Nutrition 80, 41-49.

Lissner L, Levitsky DA, Strupp BJ, Kalkwarf HJ \& Roe DA (1987) Dietary fat and the regulation of energy intake in human subjects. American Journal of Clinical Nutrition 46, 886-892.

Mattes R (1990) Effects of aspartame and sucrose on hunger and energy intake in humans. Physiology \& Behavior 47, 1037 1044.

Melanson KJ, Westerterp-Plantenga MS, Saris WHM \& Campfield LA (1999a) Short term regulation of food intake in humans. In Regulation of Food Intake and Energy Expenditure, pp. 37-58 [MS Westerterp-Plantenga, AB Steffens and A Tremblay, editors]. Milan: EDRA.

Melanson KJ, Westerterp-Plantenga MS, Saris WHM \& Campfield LA (1999b) Blood glucose patterns and appetite in time-blinded humans: Carbohydrate versus fat. American Journal of Physiology 277, R337-R345.

Melanson KJ, Westerterp-Plantenga MS, Saris WHM \& Campfield LA (1999c) Blood glucose and meal patterns in time-blinded males, after aspartame, carbohydrate, and fat consumption, related to sweetness perception. British Journal of Nutrition 82, 437-446.

Poppit \& Prentice (1996) Energy density and its role in the control of food intake: evidence from metabolic and community studies. Appetite 26, 153-174.

Rayner DV (1992) Gastrointestinal satiety in animals other than man. Proceedings of the Nutrition Society 51, 1-6.

Rogers PJ, Carlyle J, Hill AJ \& Blundell JE (1988) Uncoupling sweet taste and calories: Comparison of the effects of glucose and three intense sweeteners on hunger and food intake. Physiology \& Behavior 43, 547-552.

Rogers PJ, Pleming HC \& Blundell JE (1990) Aspartame ingested without tasting inhibits hunger and food intake. Physiology \& Behavior 47, 1239-1243.

Rolls BJ (1995) Carbohydrates, fats and satiety. American Journal of Clinical Nutrition 61, 960S-967S.

Rolls BJ \& Bell EA (1999) Intake of fat and carbohydrate: role of 
energy density. European Journal of Clinical Nutrition 53, S166-S173.

Rolls BJ, Kim S \& Fedoroff IC (1990) Effects of drinks sweetened with sucrose or aspartame on hunger, thirst, and food intake in men. Physiology \& Behavior 48, 19-26.

Spiegel TA (1973) Caloric regulation of food intake in man. Journal of Comparative Physiology and Psychology 84, 24-37.

Stubbs RJ, Harbron CG \& Prentice AM (1996) Covert manipulation of the dietary fat to carbohydrate ratio of isoenergetically dense diets: effect on food intake in feeding men ad libitum. International Journal of Obesity and Related Metabolic Disorders 20, 651-660.

Stubbs RJ, Johnstone AM, Harbron CG \& Reid C (1998a) Covertly manipulation of energy density of high carbohydrate diets in 'pseudo free-living' humans. International Journal of Obesity and Related Metabolic Disorders 22, 885-892.

Stubbs RJ, Johnstone AM, O'Reilly LM, Barton K \& Reid C $(1998 b)$ The effect of covertly manipulating the energy density of mixed diets on ad libitum food intake in 'pseudo free-living' humans. International Journal of Obesity and Related Metabolic Disorders 22, 980-987.

Stubbs RJ, Raben A \& Westerterp-Plantenga MS (1999) Macronutrient metabolism and appetite. In Regulation of Food Intake and Energy Expenditure, pp. 59-84 [MS Westerterp-Plantenga, AB Steffens and A Tremblay, editors]. Milan: EDRA.

Stubbs RJ, Ritz P, Coward WA \& Prentice AM (1995) Covert manipulation of the ratio of dietary fat to carbohydrate and energy density: effect on food intake and energy balance in free living men eating ad libitum. American Journal of Clinical Nutrition 62, 330-337.

Voorlichtingsbureau voor de Voeding (1992) De handleiding van de Voedingswijzer (The manual for the nutrition indicator). Den Haag: The Information Office for Nutrition.

Westerterp-Plantenga MS (2000a) Eating behaviour in humans, characterized by cumulative food intake curves - a review. Neuroscience and Biobehavioral Reviews 24, 239-248.

Westerterp-Plantenga MS (2000b) Adaptation of energy intake to energy expenditure in humans. Proceedings of the Nutrition Society 59, 122A.

Westerterp-Plantenga MS, Pasman WJ, Yedema MJW \& Wijckmans-Duijsens NEG (1996a) Energy intake adaptation of food to extreme energy densities of food by obese and non-obese women. European Journal of Clinical Nutrition 50, 401-407.

Westerterp-Plantenga MS, Rolland V, Wilson SAJ \& Westerterp KR (1999) Satiety related to $24 \mathrm{~h}$ diet-induced thermogenesis during high protein/carbohydrate vs high fat diets measured in a respiration chamber. European Journal of Clinical Nutrition 53, 495-502.

Westerterp-Plantenga MS, van den Heuvel E, Wouters L \& ten Hoor F (1992a) Accuracy of estimates of forthcoming ingestion as a function of menu familiarity and dietary restraint. Appetite 18, 101-109.

Westerterp-Plantenga MS, van den Heuvel E, Wouters L \& ten Hoor F (1992b) Diet induced thermogenesis and cumulative food intake curves, as a function of familiarity with food and dietary restraint in humans. Physiology and Behavior 51, 457-465.

Westerterp-Plantenga MS, van de Ven M, Wouters L \& Saris WHM (1996b) Satiation and satiety related to eating rate and meal characteristics in obese and non-obese restrained and unrestrained eating women. International Journal of Obesity and Related Metabolic Disorders 20, 105.

Westerterp-Plantenga MS \& Verwegen CRT (1999) The appetizing effect of an aperitif in overweight and normal weight humans. American Journal of Clinical Nutrition 69, 205-212.

Westerterp-Plantenga MS, Westerterp KR, Nicolson NA, Mordant A, Schoffelen PFM \& ten Hoor F (1990a) The shape of the cumulative food intake curve in humans, during basic and manipulated meals. Physiology and Behavior 47, 569-576.

Westerterp-Plantenga MS, Wijckmans-Duijsens NEG, Ten Hoor F \& Weststrate JA (1997a) Effect of replacement of fat by nonabsorbable fat (sucrose polyester) in meals or snacks as a function of dietary restraint. Physiology and Behavior 61, 939947.

Westerterp-Plantenga MS, Wijckmans-Duijsens NEG, Verboeketvan de Venne WPG, de Graaf K, van het Hof KH \& Weststrate JA (1998) Energy intake and body weight effects of six months reduced or full fat diets, as a function of dietary restraint. International Journal of Obesity and Related Metabolic Disorders 22, 14-22.

Westerterp-Plantenga MS, Wijckmans-Duijsens NEG, Verboeketvan de Venne WPG, de Graaf K, Weststrate JA \& van het Hof KH (1997b) Diet-induced thermogenesis and satiety in humans after full-fat and reduced-fat meals. Physiology and Behavior 61, 343-349.

Westerterp-Plantenga MS, Wouters L \& ten Hoor F (1990b) Deceleration in cumulative food intake curves, changes in body temperature and diet-induced thermogenesis. Physiology and Behavior 48, 831-836.

Yeomans MR (1996) Palatability and the micro-structure of feeding in humans: the appetizer effect. Appetite 27, 119-133. 